\title{
Corrigendum: An Integrated Management Model of Patients With Atrial Fibrillation: The Experience of the Local Health Unit Tuscany North-West
}

Casolo G, Cavirani G, Del Carlo A, Iannazzo S, Pardini M, Squillace A. An Integrated Management Model of Patients With Atrial Fibrillation: The Experience of the Local Health Unit Tuscany North-West. Farmeconomia. Health economics and therapeutic pathways 2019; 20(Suppl 1): 3-16; https://doi.org/10.7175/fe.v20i1S.1454

There was an error in the Figure 5 description of GLORIA-AF registry program at page 11 in this Supplement by Casolo et al. [Farmeconomia. Health economics and therapeutic pathways 2019; 20(Suppl 1): 3-16; https://doi.org/10.7175/fe.v20i1S.1454]. The online version has been corrected on April 21, 2020, as shown below.

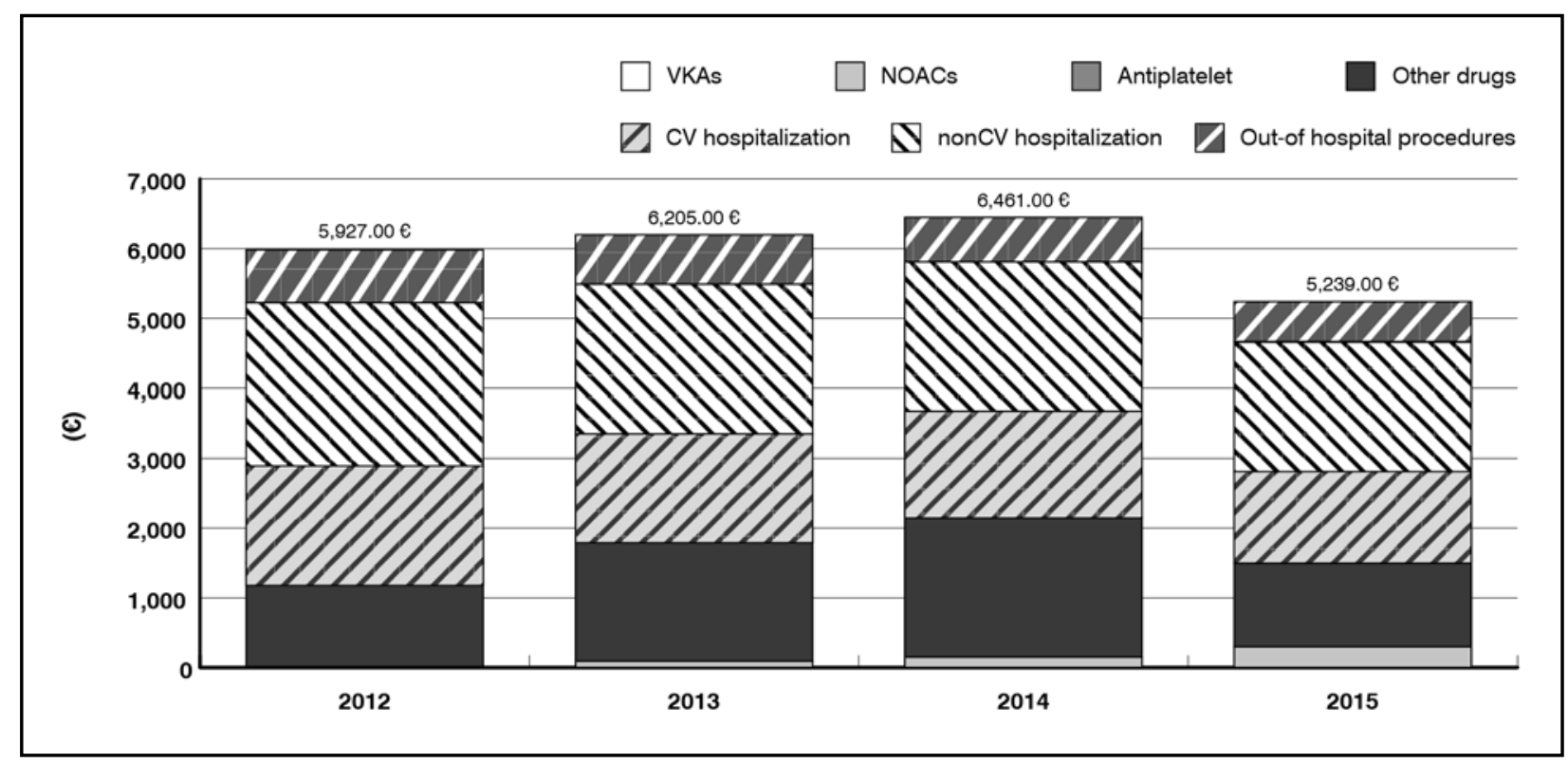

We apologize for any inconvenience caused. 